\title{
THYROID SURGERY IN GERIATRIC PATIENT: EXPERIENCE IN A TERTIARY CARE CENTRE IN RURAL KERALA
}

Jomine Jose ${ }^{1}$, Vergis Paul2 ${ }^{2}$ Najeeb Mohammad ${ }^{3}$, Neeraja Raj ${ }^{4}$

\section{HOW TO CITE THIS ARTICLE:}

Jomine Jose, Vergis Paul, Najeeb Mohammad, Neeraja Raj."Thyroid Surgery in Geriatric Patient: Experience in a Tertiary Care Centre in Rural Kerala". Journal of Evolution of Medical and Dental Sciences 2014; Vol. 3, Issue 46, September 22; Page: 11166-11169, DOI: 10.14260/jemds/2014/3456

ABSTRACT: OBJECTIVE: To study about additional risks associated with thyroid surgery in the elderly population. DESIGN: Retrospective analysis of a prospective documented data in consecutive patients undergoing thyroid surgery from January 2012 to June 2014 in a tertiary care health center. PATIENTS: The study included patients aged 30 to 40 years as control group and patients of 60 years and above who underwent thyroidectomy. MAIN OUTCOME MEASURES: Pathology reports, complications (including rates of temporary and permanent hypocalcemia and stridor, seroma/hematoma, and duration of hospital stay. RESULTS: There were 68 patients of 30-40 age group who under-went thyroidectomy between January 2012 and June of 2014; 46 elderly patients underwent surgery during that same time frame. There were no deaths in both cohort, and no cases of permanent TVF paralysis. The elderly patients had a similar rate of complications when compared with the younger patients, (60\% vs $70 \%$ ) but a higher duration of hospital stay (6.9 vs 5.4). CONCLUSIONS: Thyroid surgeons will be faced more often with the prospect of elective thyroid surgery in patients of advanced age, as an increasingly aged population emerges and the prevalence of thyroid nodules and thyroid cancer increases. Thyroid surgery in optimized elderly patients is safe and no more dangerous, than surgery in younger patients though the duration of hospital stay is more.

KEYWORDS: Thyroid surgery, geriatrics.

INTRODUCTION: There is no standard definition for geriatric age group ${ }^{1}$. WHO defines the geriatric age group as the age above 60 years of age. ${ }^{2}$ The world population of older people is on the rise and hence more and more older people are coming for surgery but the willingness of physicians to refer patients to surgery diminishes with increasing age of the patient.1,4

Surgery in elderly patients has been considered to be more hazardous than in a younger population; however, this increased risk appears to be related to the presence of co-morbidities rather than age alone. ${ }^{3}$ So, here we are considering the question, whether thyroid surgery is associated with more risk in the elderly.

METHODS: We collected the data of all thyroid surgeries done in MOSC medical college which is a tertiary referral center with a post-graduate teaching department of general surgery in rural Kerala, from 2012 January to 2014 June. Patients were grouped into two, those above 60years and those below 60years. All the data on transient and permanent complications and biopsy report of the patients above 60years were collected.

As a control group patients between 30 and 40 years were taken, though a cursory examination of complications of other patients was also done. Outcome measures included pathology findings, complications (including rates of temporary and permanent hypocalcaemia and temporary and permanent TVF paralysis) and duration of hospital stay. 
All patients underwent a complete and comprehensive history, physical examination, laboratory examinations, and assessment of surgical risks. All patients above 50 years or with a significant cardiac history or other substantial co-morbidity had cardiac clearance before surgery.

Co-Morbidities: Hypertension, coronary artery disease, diabetes mellitus, COPD and dyslipidemia were present singly or together in 28 out of 46 patients in the geriatric group. There was also a case with history of CVA. Two cases had toxicity. In the control group only two cases with diabetes, one with hypertension and one with both. There were two cases with toxicity.

\section{RESULTS:}

Indications of Surgery: The predominant indication of surgery was thyroid swelling due to multi nodular goiter. While all cases of elderly patients presented with multiple nodules in thyroid 15 cases in the control group presented with solitary nodule. There were a total of three cases in control group with toxicity which was secondary thyrotoxicosis.

Surgical Strategy: A total thyroidectomy was done in all cases of geriatric group owing to the fact that all patients presented with multi nodular goiter while hemi thyroidectomy was done in some case of control group as they presented with solitary nodule.

Pathology: Most of the patients had multi nodular goiter. There were also cases of papillary carcinoma and follicular carcinoma, confined to the thyroid (no extra-thyroid spread), in both groups.

\begin{tabular}{|l|c|c|}
\hline \multicolumn{1}{|c|}{ Pathology } & Control & Geriatric \\
\hline \multicolumn{1}{|c|}{ Total } & $\mathbf{6 8}$ & $\mathbf{4 6}$ \\
\hline MNG & 37 & 30 \\
\hline MNG with adenoma & - & 3 \\
\hline MNG with Lymphocytic thyroiditis & 11 & 3 \\
\hline Hashimoto's thyroiditis & 2 & 2 \\
\hline Lymphocytic thyroiditis & - & 1 \\
\hline Papillary carcinoma & 3 & 1 \\
\hline Follicular carcinoma & 3 & 1 \\
\hline MNG with papillary carcinoma & 2 & 3 \\
\hline MNG with follicular carcinoma & 2 & 2 \\
\hline Follicular adenoma & 8 & - \\
\hline
\end{tabular}

There were 4 male patients in the geriatric group and four in the control. In the control group one had papillary carcinoma and the other follicular carcinoma. Follicular carcinoma presented as MNG while papillary as SNT, one had toxic MNG and another MNG with lymphocytic thyroiditis. In the geriatric group one had Hashimoto's thyroiditis, one MNG and one follicular and one papillary carcinoma.

COMPLICATIONS: The most common complication in geriatric group was transient hypocalcaemia (22-48\%). There were three cases of transient stridor which got improved. Three cases had seroma 
formation that got corrected by needle aspiration. One patient had non-thyroid related complicationischemic heart disease (inferior wall myocardial infarction) after the surgery.

In the control group also the most common complication was transient hypocalcaemia (47$69 \%$ ). There was one case of permanent hypocalcaemia in control group. The difference of hypocalcaemia has a p value of 0.02 which is statistically significant. There was one case with seroma in the control group but no cases of stridor have a $\mathrm{p}$ value of more than 0.3 and not significant.

The significant difference between both groups was in the duration of hospital stay. The average hospital stay was 6.9 in the geriatric group while 5.4 in control group.

The significant difference was due to prolonged hypocalcaemia that needed intravenous correction, prolonged drain or both and in some cases pre-operative optimization. (All the cases had pre tracheal drain institution and the patients were discharged after removing the drain only). This has a $\mathrm{p}$ value less than 0.0001 which is extremely statistically significant.

DISCUSSION: There are only a few studies comparing thyroid surgery in geriatric patients. While most studies (Christian Passler et al, ${ }^{1}$ Melanie W. Seybt et al, ${ }^{3}$ Michael C. Sullivan et al, ${ }^{4}$ Ríos A et al5and Rodríguez et $\mathrm{al}^{6}$ ) found that there is no greater risk for thyroid surgery in the elderly. One study (Mekel et al) ${ }^{7}$ found a higher increase in morbidity in older group.

Our study also conforms to the above studies. We also found that though morbidity is more in elderly patients, thyroid surgery is still a safe surgery. While transient hypocalcaemia $(47.8 \%$ vs $69 \%$ ) is found to be less in older people (statistically significant), transient stridor (6.5\% vs $0.01 \%$ ), and seroma (6.5\% vs $0 \%)$ that required aspiration are more in older people (statistically nonsignificant).

Though there was no death, non-thyroid related complication can occur in the elderly7. In our study the only non-thyroid complication was IHD that occurred in 63yrs old with no co morbidities, while in other studies such complications are more in octogenerians. ${ }^{7}$ We also found that in the foreign studies most patients are above 70 years of age, most of our patients are between 60-70 years. Only one patient was above 80 years.

There were only four males in the study group and 4 in control. Out of the males, two in study group had malignancy while the two in control had malignancy. Though most patients in foreign studies ${ }^{5}$ underwent surgery for compression or toxic symptoms, all the patients here underwent surgery for swelling in the neck except four patients who had toxicity in addition to swelling.

CONCLUSIONS: Thyroid surgeons will be faced more often with the prospect of elective thyroid surgery in patients of advanced age as an increasingly aged population emerges and the prevalence of thyroid nodules and thyroid cancer increases. Thyroid surgery in optimized elderly patients is safe and no more dangerous than surgery in younger patients though the duration of hospital stay is more.

We found, within the limits of a retrospective review, that elective thyroid surgery in elderly patients is safe and that age alone should not be a consideration when deciding whether or not to operate. We also found that though the incidence of hypocalcaemia is less in elderly though the severity is more, the cause of which needs further studies.

As patients presenting with even multi nodular goiter can harbor a malignancy, thyroidectomy should be advised to all irrespective of the age, especially in males, as thyroidectomy is a safe surgery in the elderly compared to younger patients. 


\section{RECOMMENDATION:}

1. Older patients should be warned of a prolonged hospital stay and the probable need for intravenous calcium administration

2. A community based study is recommended to identify whether the prevalence of thyroid disease is less in the elderly (above 80) or is it the reluctance of the patients to undergo treatment that reduced the number of such patients.

3. It is also recommended to study whether a thyroid surgery without any symptoms of toxicity or compression in elderly patients will change the quality of the life.

\section{REFERENCES:}

1. Passler T C, Avanessian R, Kaczirek K, Prager G, Scheuba C, Niederie B: Thyroid Surgery in Geriatric patient: Arch Surg 2002; 137: 1243-1248.

2. Ageing. Available from URL: http://www.who.int/healthinfo/survey/ageingdefnolder/en/

3. Melanie W. Seybt, MD; Sunny Khichi, BS; David J. Terris, MD: Geriatric Thyroidectomy, Safety of Thyroid Surgery in an Aging Population: Arch Otolaryngol Head Neck Surg. 2009;135 (10):1041-1044.

4. Michael C. Sullivan, Sanziana A et al: Clinical and Economic Outcomes of Thyroid Surgery in Elderly Patients: A Systematic Review Journal of Thyroid Research 2012; 2012: 615846.

5. Ríos A, Rodríguez JM, Galindo PJ, Canteras M, Parrilla P: Surgical treatment for multinodular goiters in geriatric patients. Langenbecks Arch Surg2005, 390:236-242.

6. Raffaelli M, Bellantone R, Princi P, De Crea C, Rossi ED, Fadda G, Lombardi PC: Surgical treatment of thyroid diseases in elderly patients. American Journal of Surgery2010, 200:4467472.

7. Mekel M, Stephen AE, Gaz RD, Perry ZH, Hodin RA, Parangi S: Thyroid surgery in octogenarians is associated with higher complication rates. Surgery 2009, 146:913-21.

\section{AUTHORS:}

1. Jomine Jose

2. Vergis Paul

3. Najeeb Mohammad

4. Neeraja Raj

\section{PARTICULARS OF CONTRIBUTORS:}

1. Assistant Professor, Department of General Surgery, MOSC Medical College, Kolenchery.

2. Professor and Unit Chief, Department of General Surgery, MOSC Medical College, Kolenchery.

3. Post Graduate Student, Department of General Surgery, MOSC Medical College, Kolenchery.

\section{Intern, Department of General Surgery,} MOSC Medical College, Kolenchery.

\section{NAME ADDRESS EMAIL ID OF THE CORRESPONDING AUTHOR:}

Dr. Jomine Jose,

Assistant Professor,

Department of General Surgery, MOSC Medical College,

Kolenchery, Ernakulam-682311.

Email: jomine9@gmail.com

Date of Submission: 02/09/2014.

Date of Peer Review: 03/09/2014.

Date of Acceptance: 11/09/2014.

Date of Publishing: 19/09/2014. 